\title{
Preparation of Bi2Sr2CaCu2Ox Thin Film By Pulsed Laser Deposition For Optoelectronic Devices Application
}

Raid Ismail ( $\square$ raidismail@yahoo.com )

University of Technology https://orcid.org/0000-0002-6629-3630

N. Hasan

University of Technology,Iraq

Suaad S. Shaker

University of Technology,Iraq

\section{Research Article}

Keywords: BSCCO film, Laser deposition, Laser energy density, Photodetector

Posted Date: February 10th, 2021

DOl: https://doi.org/10.21203/rs.3.rs-179588/v1

License: (1) This work is licensed under a Creative Commons Attribution 4.0 International License.

Read Full License

Version of Record: A version of this preprint was published at Silicon on March 15th, 2021. See the published version at https://doi.org/10.1007/s12633-021-01061-z. 


\title{
Preparation of $\mathrm{Bi}_{2} \mathrm{Sr}_{2} \mathrm{CaCu}_{2} \mathrm{O}_{x}$ thin film by pulsed laser deposition for optoelectronic devices application
}

\author{
Raid A. Ismail, N. Hasan, Suaad S. Shaker \\ Applied Science Department, University of Technology, Baghdad, Iraq
}

\begin{abstract}
In this study, we have prepared $\mathrm{Bi}_{2} \mathrm{Sr}_{2} \mathrm{CaCu}_{2} \mathrm{O}_{x}$ (BSCCO) nanostructure films by pulsed laser deposition technique (PLD). The structural and optical properties of nanostructured $\mathrm{Bi}_{2} \mathrm{Sr}_{2} \mathrm{CaCu}_{2} \mathrm{O}_{\mathrm{x}}$ film were investigated. X-ray diffraction (XRD) studies of the films prepared at 6.5 and $8 \mathrm{~J} / \mathrm{cm}^{2}$ showed that the films are crystalline in nature with orthorhombic phase. Scanning electron microscopy (SEM) investigation confirmed that the deposited film has spherical grains and the mean grain size of the film increased from $150 \mathrm{~nm}$ to $250 \mathrm{~nm}$ as laser energy density increased from 6.5 to $8 \mathrm{~J} / \mathrm{cm}^{2}$. The optical energy gap of the film decreased from 2.24 to $1.7 \mathrm{eV}$ when the energy density increased. The optoelectronic properties of the $\mathrm{Bi}_{2} \mathrm{Sr}_{2} \mathrm{CaCu}_{2} \mathrm{O}_{\mathrm{x}} / \mathrm{Si}$ heterojunction photodetector have been investigated. The photodetectors exhibited rectification properties and the ideality factor of the photodetectors deposited 6.5 and 8 $\mathrm{J} / \mathrm{cm}^{2}$ were 2.3 and 4.2 , respectively. The on/off ratio of the photodetectors was found to be 761 and 385 for the photodetectors prepared with6.5 and $8 \mathrm{~J} / \mathrm{cm}^{2}$, respectively. A responsivity of 514 $\mathrm{mA} / \mathrm{W}$ at $860 \mathrm{~nm}$ was found for the photodetector prepared with $6.5 \mathrm{~J} / \mathrm{cm}^{2}$ without using post annealing and/or buffer layer.
\end{abstract}

Keywords: BSCCO film; Laser deposition; Laser energy density; Photodetector

\section{1- Introduction}

Since the discovery of the bismuth-based superconductors Bi-Sr-Ca-Cu-O (BSCCO) compound [1], have considered being a significant for many industrial applications bulk or thin films due to their superior electrical and magnetic properties [2-7]. The advantage of Bi-based oxides is available, not poisonous, also contains no rare-earth element, relatively stable in atmosphere pressure, thermal and chemical stability, not deformed on cooling and less sensitive to deal with water. Though BSCCO is high temperature superconductor materials; the 
phenomenon of superconductivity [8] is exhibited in vanishing electrical resistivity of the material when it is cooled to a certain temperature called critical temperature $\left(T_{c}\right)$ [9]. The critical temperature of BSCCO is in the range (105) k and (80-85) k for Bi-2212 and Bi-2232, respectively. Therefore, it is essential to fabricate a thin film for the growth of each pure phase for BSCCO thin film applications [10,11]. Beside the electrical properties of the BSCCO film, the energy gap of BSCCO film was around $2 \mathrm{eV}$ at room temperature which can be useful for optoelectronic applications. Many methods were used to deposit BSCCO thin film, for example, metal organic chemical vapor deposition (MOCVD), molecular beam epitaxy (MBE), coevaporation, non-vacuum route, and pulsed laser deposition (PLD) [12-13]. PLD technique has many advantages compared to other methods; it is simple, cost-effective, used to deposit multicomponents film, good adhesion of film to the substrate, good control on film thickness [14]. It is reported that the laser parameters such as energy density, wavelength and pulse duration affecting the properties of the deposited films $[15,16]$. Up to best of our knowledge, no data have been reported on the optoelectronic properties of BSCCO film. Herein, we report on fabrication of $\mathrm{Bi}_{2} \mathrm{Sr}_{2} \mathrm{CaCu}_{2} \mathrm{O}_{\mathrm{x}} / \mathrm{Si}$ photodetector by pulsed laser deposition (PLD) technique. The structural and optical properties of BSCCO as well as the figures of merit of the BSCCO/Si photodetector were investigated at room temperature as a function of laser energy density.

\section{2-Experimental}

Thin films of $\mathrm{Bi}_{2} \mathrm{Sr}_{2} \mathrm{CaCu}_{2} \mathrm{O}_{\mathrm{x}}$ were deposited by using home-made pulsed laser deposition system consisting of glass bell jar, Nd:YAG laser and rotary pump. The laser used for deposition of the BSCCO films was Nd:YAG operating at $532 \mathrm{~nm}$ (second harmonic generation $\mathrm{Nd}: \mathrm{YAG}$ ) and pulsed duration of $7 \mathrm{~ns}$. The target that we used is $\mathrm{Bi}(\mathrm{Pb})-\mathrm{Sr}-\mathrm{Ca}-\mathrm{Cu}-\mathrm{O}$ of adding $\mathrm{PbO}$ with $5 \mathrm{wt} \%$, to the compound. The deposition was carried out in the vacuum with vacuum pressure of down than $2.0 \times 10^{-3}$ mbar. The laser beam was focused onto a BSCCO target (99.99\% purity) of using positive lens of $10 \mathrm{~cm}$ focal length. The substrates used in this work were glass and silicon, the silicon was p-type with orientation of (100) and electrical resistivity of $1-3 \Omega . c m$. The distance between target and substrate was adjusted to be $5 \mathrm{~cm}$. The values of laser energy density used to prepare the films were 6.5 and $8 \mathrm{~J} / \mathrm{cm}^{2}$ and the substrate temperature fixed at $60{ }^{\circ} \mathrm{C}$. The

structure of the film was examined using x-ray diffractometer (XRD-6000, Shimadzu). The surface morphology of the film was investigated using scanning electron microscope SEM 
(T-scan Vega III Czech). The optical transmission of the film was measured using UV-Vis spectrophotometer (Metertech, SP8001).BSCCO/p-Si photodetector was fabricated by deposition a thin film of BSCCO film on Si substrate with area of $1 \mathrm{~cm}^{2}$ and the ohmic contacts were made by depositing of $\mathrm{Al}$ and In thin films on BSCCO film and back side of silicon substrate, respectively, by using thermal evaporation technique through mask. The schematic diagram of cross sectional view of BSCCO/p-Si with electrical configuration is shown in Fig.1. The currentvoltage characteristics under dark and illumination conditions were investigated at room temperature. The responsivity of the photodetector was measured using monochromator (Jobin Yvon).

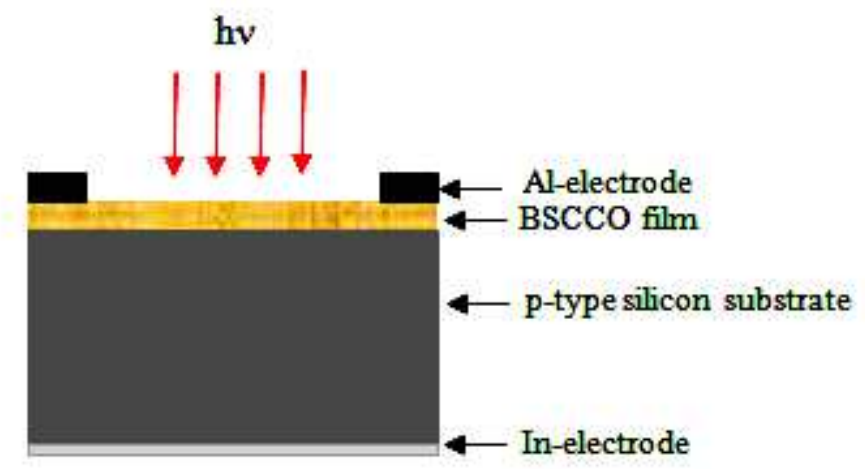

Fig. (1) The schematic diagram of cross sectional view of BSCCO/p-Si

\section{Results and discussion}

Fig.2-a shows the XRD patterns of BSCCO films prepared at laser energy density of 6.5 and 8 $\mathrm{J} / \mathrm{cm}^{2}$ with the same thickness $(350 \mathrm{~nm})$. The XRD of BSCCO film deposited at $6.5 \mathrm{~J} / \mathrm{cm}^{2}$ showed the presence of five peaks at $17.4,39.4^{\circ}, 45.6^{\circ}$, and $66^{\circ}$ corresponded to (006), (0014), (0016), and (0020) plane, respectively. All these peaks are indexed to well-crystallized BSCCO film with orthorhombic phase. The observed peaks confirmed that the grains of the BSCCO film are highly oriented along the c-axis. $[17,18]$. The XRD pattern also shows the presence of a small peak related to the $\mathrm{Bi}-2201$ phase located at $13.8^{\circ}$. Increasing the laser energy density from 6.5 $\mathrm{J} / \mathrm{cm}^{2}$ to $8 \mathrm{~J} / \mathrm{cm}^{2}$ resulted in remarkable increasing of the intensity of (006) peak and a new peak at 25.6 corresponded to (008) plane was observed. The XRD peaks at $39.4^{\circ}, 45.6^{\circ}$, and $66^{\circ}$ were disappeared. The reason beyond this result may be ascribed to the preferred orientation along 
(006) plane which comes from varying the growth mechanism with increasing the laser fluence. No other peaks related to the nonstoichiometric phases or impurities have been detected in the XRD pattern.

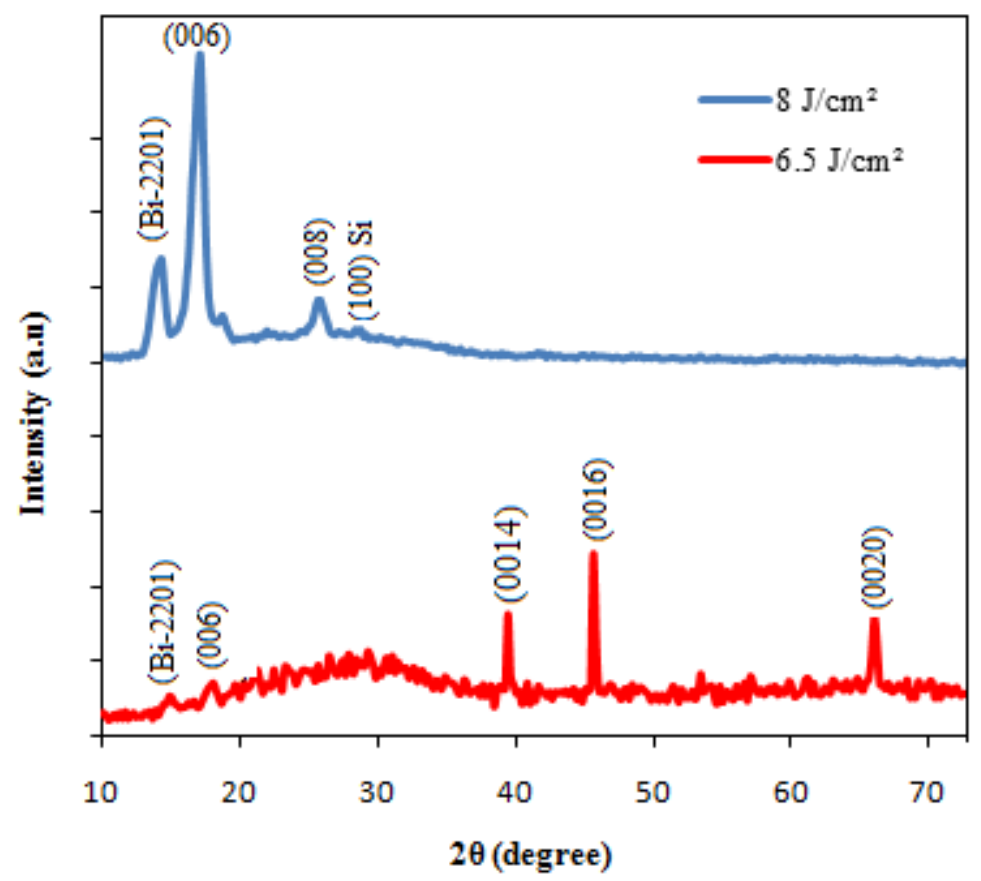

Fig. (2) XRD of BSCCO films prepared at laser energy density of 6.5 and $8.1 \mathrm{~J} / \mathrm{cm}^{2}$

The average crystallite size of the BSCCO film was determined for (006) plane by using Scherrer equation and found to be 66 and 100nm for film grown with 6.5 and $8 \mathrm{~J} / \mathrm{cm}^{2}$, respectively. Fig. 3 shows the SEM images with two magnifications of BSCCO film deposited on the silicon substrate with 6.5 and $8 \mathrm{~J} / \mathrm{cm}^{2}$. The film grown at $6.5 \mathrm{~J} / \mathrm{cm}^{2}$ shows the presence of complete spherical grains with different sizes that distributed randomly on the film surface. The average grain size which determined by image $\mathrm{J}$ software was $150 \mathrm{~nm}$. No change in the surface morphology of the film deposited at $8 \mathrm{~J} / \mathrm{cm}^{2}$ was observed and the average grain size was 250 nm. Increasing the laser energy leads to increasing the evaporated volume and the grains agglomeration is increased. Micro-sized grains with spherical shape were detected on the surface of the film deposited with $8 \mathrm{~J} / \mathrm{cm}^{2}$. As clearly seen from Fig.3, the agglomerated and the clustering grains have larger sizes and irregular shapes as well as the presence of particulates 

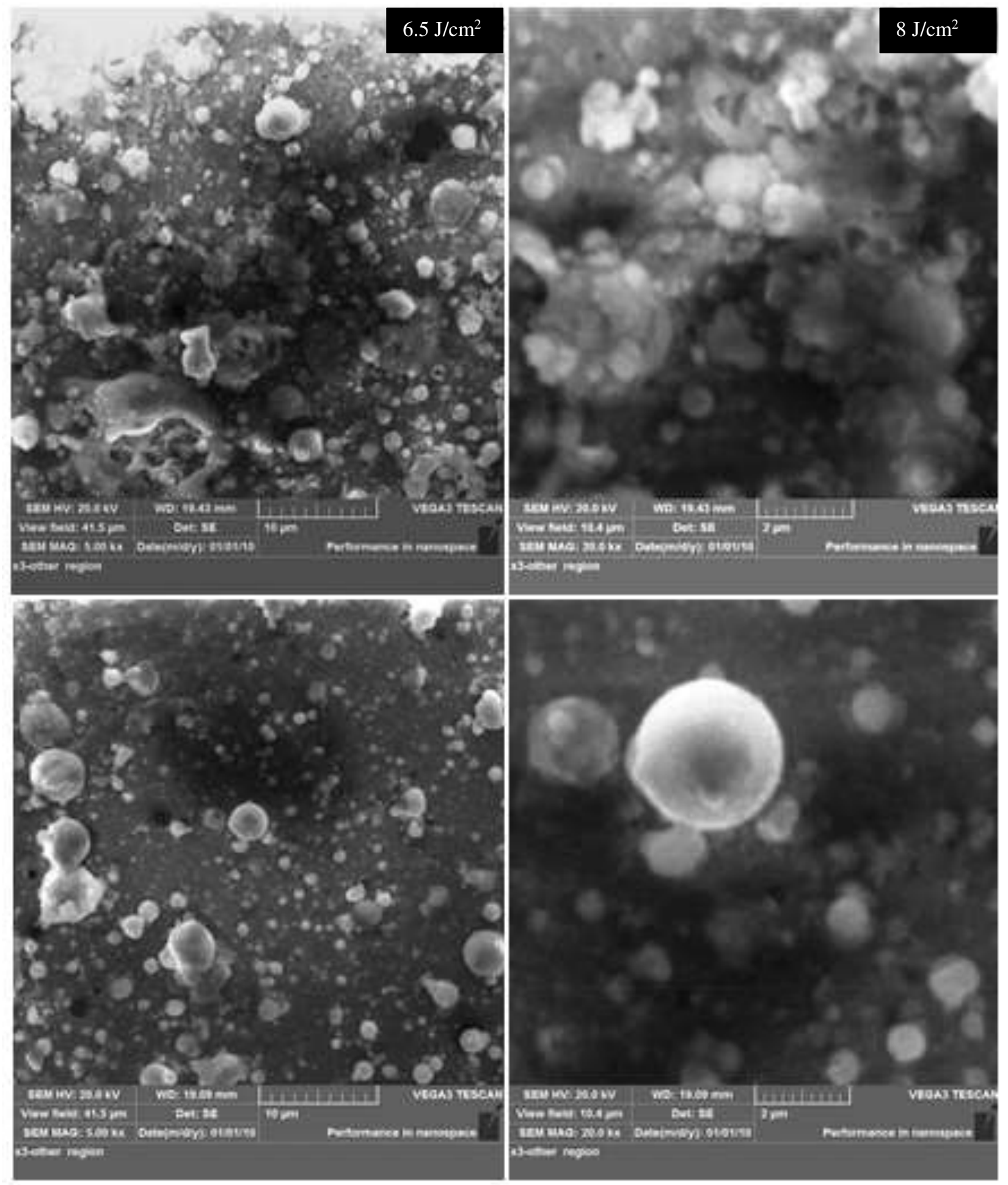

or/and droplets due to the effect of laser splashing was also observed on the film surface.

Fig. (3) SEM images with two magnifications of BSCCO/Si film deposited with 6.5 and $8 \mathrm{~J} / \mathrm{cm}^{2}$

Fig.3 shows that the surfaces of the deposited films have no microcracks and porosities. The EDX spectra of the films is shown in Fig. It showed the presence of $\mathrm{Bi}, \mathrm{Sr}, \mathrm{Ca}, \mathrm{Cu}$, and $\mathrm{O}$ 
elements which all indexed to the BSCCO film and the origin of the other elements $\mathrm{C}, \mathrm{Na}$ and $\mathrm{Mg}$ is the SEM chamber.
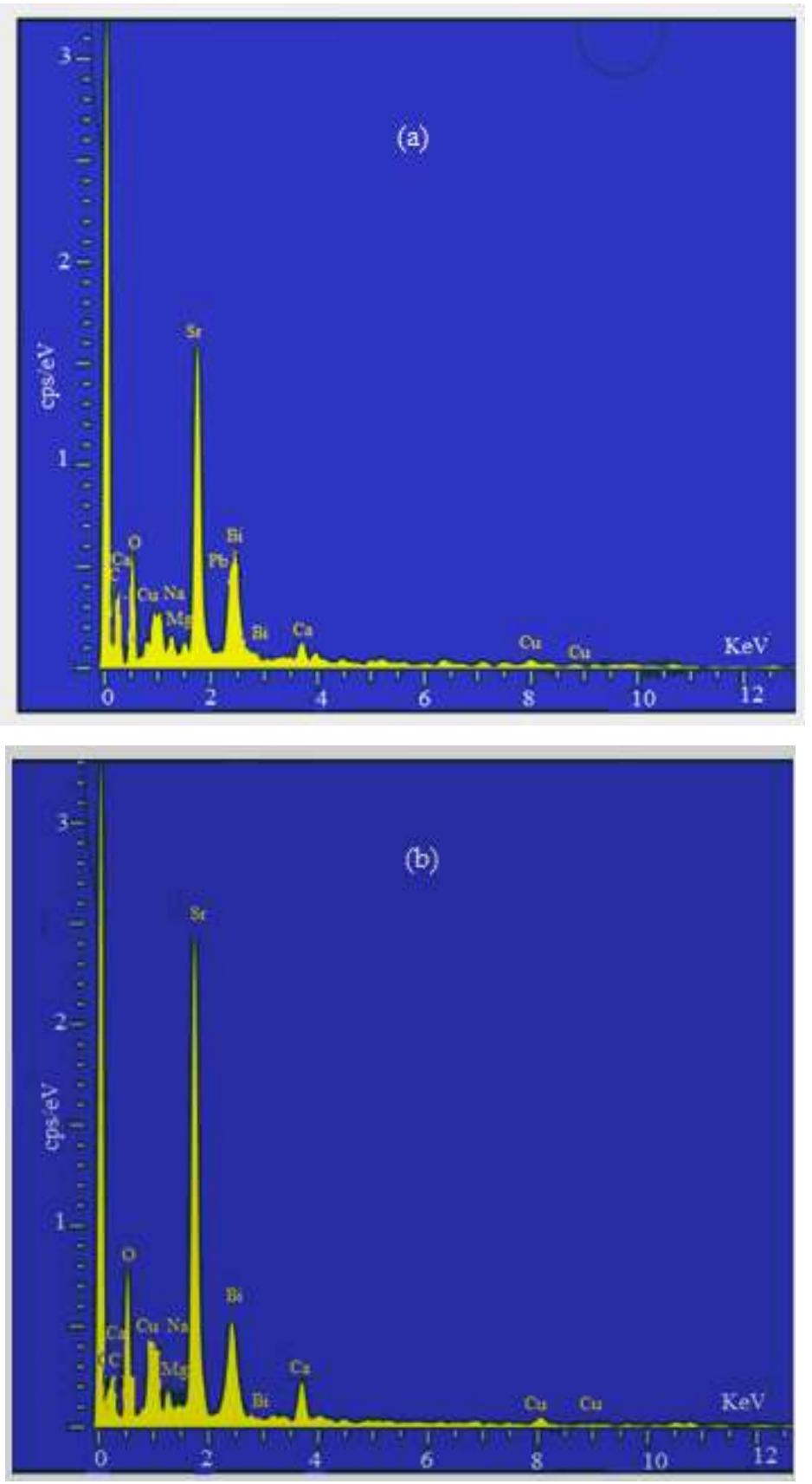

Fig. (4) EDX spectra of BSCCO/Si film deposited with(a) $6.5 \mathrm{~J} / \mathrm{cm}^{2}$ and (b) $8 \mathrm{~J} / \mathrm{cm}^{2}$ 
Fig.5-a displays the optical absorption of BSCCO film deposited on glass substrate. The film deposited at $6.5 \mathrm{~J} / \mathrm{cm}^{2}$ has lower optical absorption than of that deposited at $8 \mathrm{~J} / \mathrm{cm}^{2}$ with the same thickness due to the droplets and agglomeration formed at $8 \mathrm{~J} / \mathrm{cm}^{2}$. These structures act as scattering centers which lowering the film transmission. As obvious from Fig.5-a, a distinct absorption peak located at $415 \mathrm{~nm}$ for film deposited at $6.5 \mathrm{~J} / \mathrm{cm}^{2}$ and $450 \mathrm{~nm}$ for film deposition at $8 \mathrm{~J} / \mathrm{cm}^{2}$ were observed. The origin of this peak can be attributed to quantum size effect [ 19 ]. The color of the BSCCO film deposited on the glass substrate is yellowish as shown in Fig.5-b.

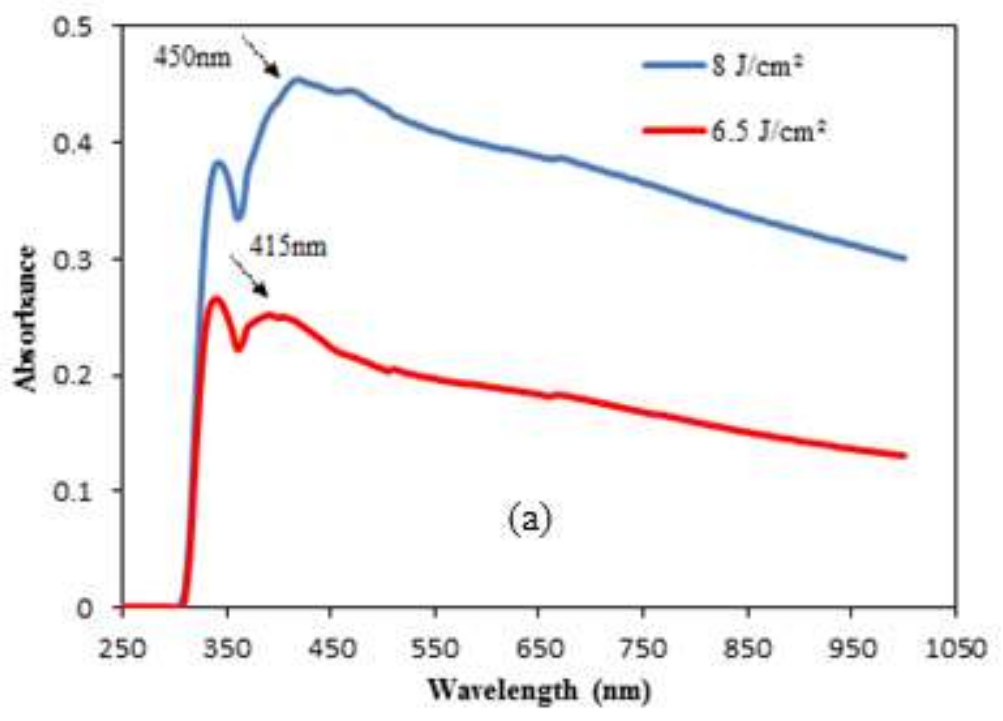

(b)

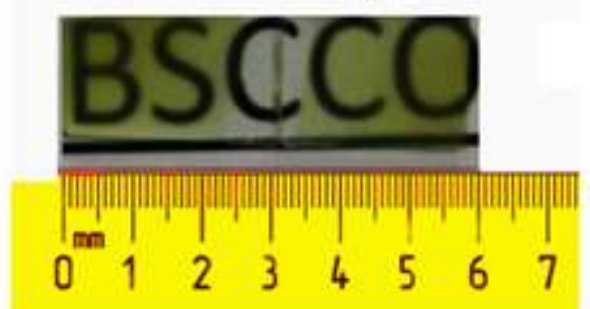

Fig.5. (a) Optical absorption of BSCCO/glass films deposited with $6.5 \mathrm{~J} / \mathrm{cm}^{2}$ and $8 \mathrm{~J} / \mathrm{cm}^{2}$ and (b) photograph of BSCCO films deposited on the glass substrate

The reflectance spectra of BSCCO films are shown in Fig.6-a. The films reflectance is shown in Fig.6-a revealed that the film deposited at $8 \mathrm{~J} / \mathrm{cm}^{2}$ has higher reflectance than of that film prepared at $6.5 \mathrm{~J} / \mathrm{cm}^{2}$. This can ascribe to particulates and droplets formed at higher laser energy density. The film reflectance decreased sharply after $300 \mathrm{~nm}$ and then tends to saturate. The 
refractive index of the film has been determined from reflectance data and plotted as a function wavelength as shown in Fig.6-b.
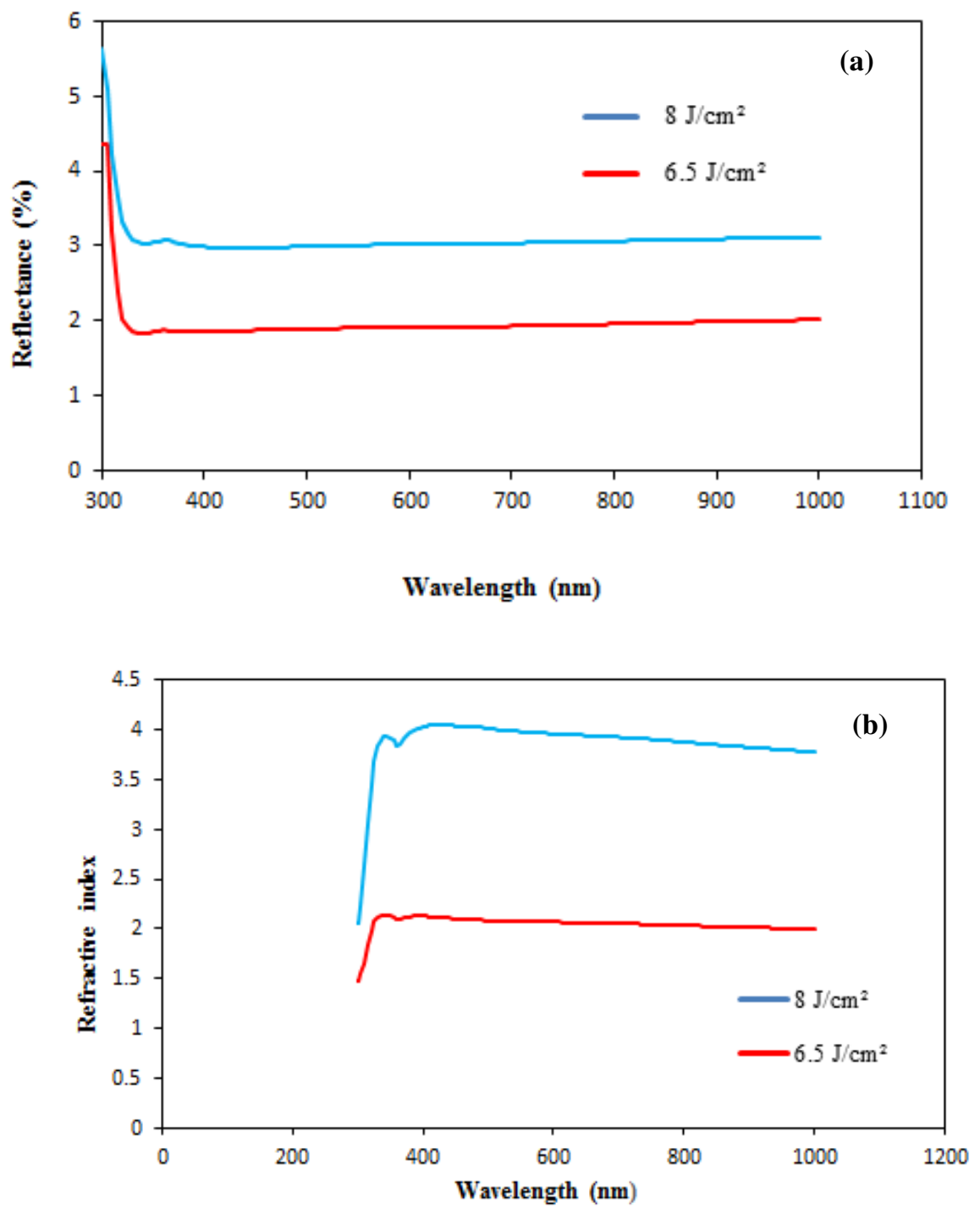

Fig.6 (a) The reflectance spectra and (b) refractive index of BSCCO films deposited with $6.5 \mathrm{~J} / \mathrm{cm}^{2}$ and 8 $\mathbf{J} / \mathrm{cm}^{2}$

To estimate the optical energy gap $\left(\mathrm{E}_{\mathrm{g}}\right)$ of BSCCO film, variation of $(\alpha h v)^{2}$ with photon energy (hv) was plotted as shown in Fig.7. The energy gap can be determined from the extrapolation of the straight line of Fig. 6 to $(\alpha h v)^{2}=0$ point according to Tauc plot for direct transition type

$$
(\alpha h v)^{2}=A\left(h v-E_{g}\right)
$$


Where $\alpha$ is the absorption coefficient, $\mathrm{h}$ is Plank constant, $v$ is the frequency, and $\mathrm{A}$ is a constant. As shown in Fig.7, the values of energy gap of BSCCO films deposited at 6.5 and $8 \mathrm{~J} / \mathrm{cm}^{2}$ were 1.65 and $2.25 \mathrm{eV}$, respectively. We attributed the decrease in the energy gap of the film after increasing the laser energy density to increasing the grain size as well as to grains agglomeration effect. The obtained values of $E_{g}$ at room temperature are in good agreement with reported data [20].

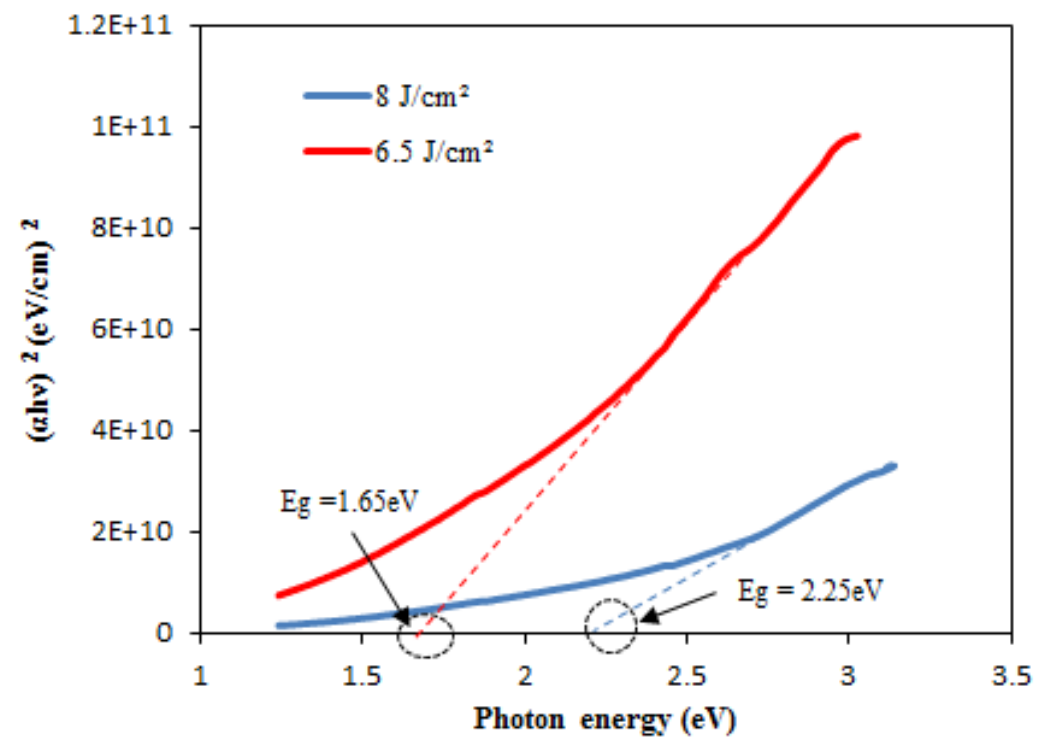

Fig. (7) optical energy gap of BSCCO film deposited with $6.5 \mathrm{~J} / \mathrm{cm}^{2}$ and $8 \mathrm{~J} / \mathrm{cm}^{2}$

Fig.8-a illustrates the dark current- voltage characteristics of BSCCO/Si heterojunction at room temperature under forward and reverse directions. Fig.8 shows the fabricated heterojunctions have rectification characteristics. The current transport mechanism in both two heterojunction is recombination-tunneling. The forward current increases as bias voltage increase due to the decreasing the depletion layer width. The forward current of BSCCO/Si heterostructure deposited at $6.5 \mathrm{~J} / \mathrm{cm}^{2}$ is larger than that of heterojunction prepared with $8 \mathrm{~J} / \mathrm{cm}^{2}$ at same bias voltage. 

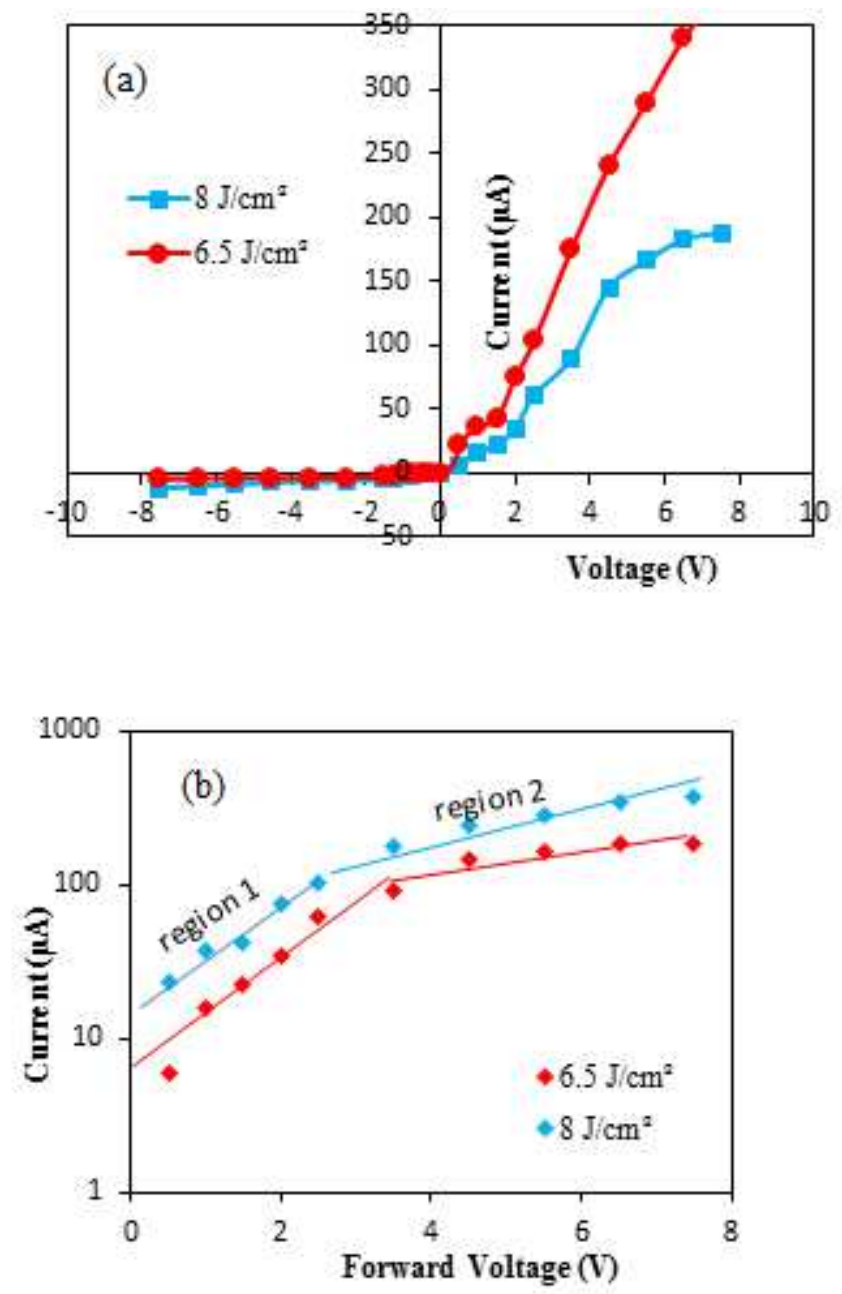

Fig.8 (a) dark I-V characteristics of BSCCO/Si heterojunction at room temperature under forward and reverse directions (b) plot of semi-logarithmic If $-\mathrm{V}$

This result could be attributed to the grains agglomeration found for film deposited at $8 \mathrm{~J} / \mathrm{cm}^{2}$ and also due to the high resistivity of BSCCO film. The electrical resistivity of the films was measured using Hall effect and it found to be $0.4 \Omega . \mathrm{cm}$ for film deposited at $6.5 \mathrm{~J} / \mathrm{cm}^{2}$ and 1 $\Omega . c m$ for film deposited at $8 \mathrm{~J} / \mathrm{cm}^{2}$. On the other hand, the forward current of the heterojunction prepared at $8 \mathrm{~J} / \mathrm{cm}^{2}$ tends to saturate after $4 \mathrm{~V}$ due to the high series resistance effect. The ideality 
factor (n) of the BSCCO/p-Si heterojunction was calculated using the following simple diode equation

$$
n=\frac{\mathrm{q}}{\mathrm{KT}}\left(\frac{\partial V}{\frac{\partial \ln I}{I_{S}}}\right)
$$

Where $I_{S}$ is the saturation current of the heterojunction which can determine from semilogarithmic $\mathrm{I}_{\mathrm{f}} \mathrm{V}$ plot as shown in Fig.8-b. The values of $\mathrm{n}$ were 2.3 and 5 (region 1) for heterojunction prepared with 6.5 and $8 \mathrm{~J} / \mathrm{cm}^{2}$, respetively. The main reason for $\mathrm{n}>1$ can be ascribed to the domination the recombination current over the diffusion current and due to the surface states at BSCCO-Si interface [21,22 ].

Fig.9 illustrates the illuminated current-voltage characteristics at room temperature and illuminated at different white light intensities. When light incident on the photodetector, it results in the increasing of the photocurrent due to the absorption of light in the depletion region and lead to produces electron-hole pair. The presence the internal and external electric fields prevent electron-hole recombination. The on/off ratio of the photodetector deposited with $6.5 \mathrm{~J} / \mathrm{cm}^{2}$ was $2.3 \times 10^{2}$ at $7.5 \mathrm{~V}$ bias and at light intensity of $10 \mathrm{~mW} / \mathrm{cm}^{2}$. Increasing the bias voltage leads to increasing the photocurrent due to widening of the depletion width.
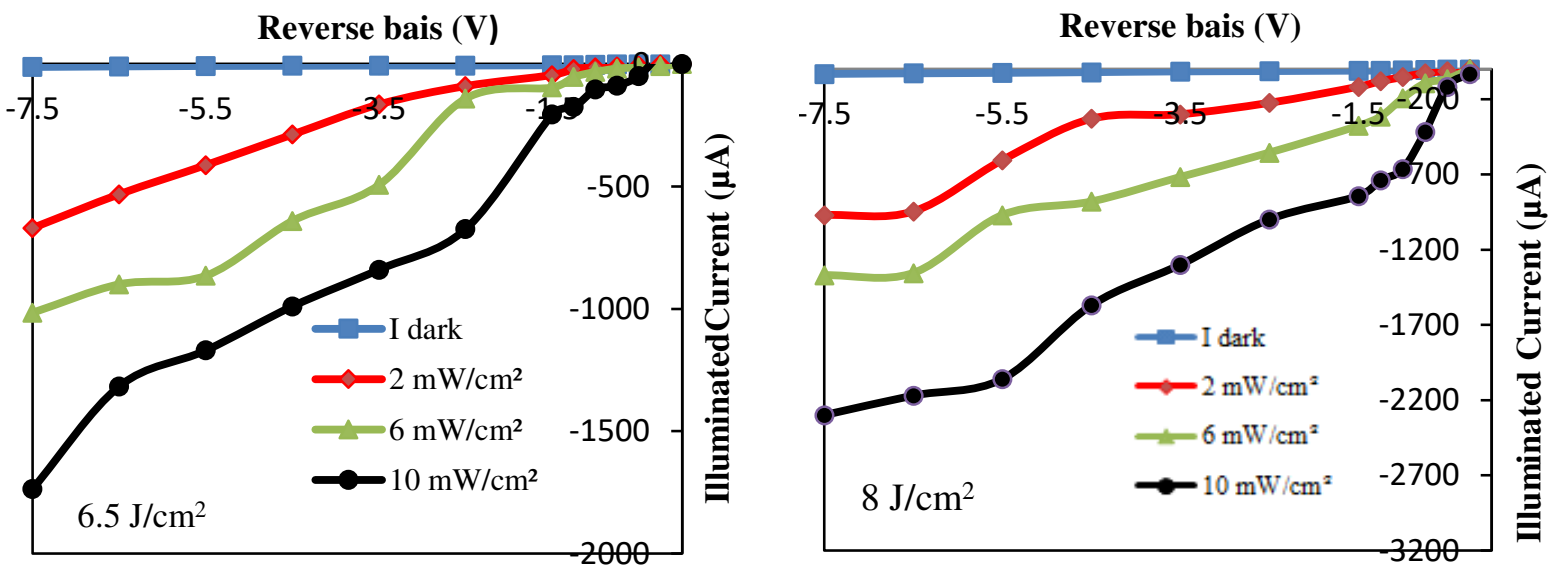

Fig.9. illuminated I-V characteristics at room temperature and different white light intensities for films deposited with $6.5 \mathrm{~J} / \mathrm{cm}^{2}$ and $8 \mathrm{~J} / \mathrm{cm}^{2}$ 
As shown in Fig.10, the photocurrent increases as light intensity increase because of increasing the number of e-h pairs which generated in the depletion region. This result indicates that the prepared photodetectors have reasonable linearity characteristics (large dynamic range). The on/off ratio of the photodetector prepared at $8 \mathrm{~J} / \mathrm{cm}^{2}$ was $1.7 \times 10^{2}$ at $7.5 \mathrm{~V}$ bias and at light intensity of $10 \mathrm{~mW} / \mathrm{cm}^{2}$. We have ascribed the decrease in the on/off ratio of the photodetector prepared with laser energy density of $8 \mathrm{~J} / \mathrm{cm}^{2}$ to the structural defects, surface states and recombination centers [23].

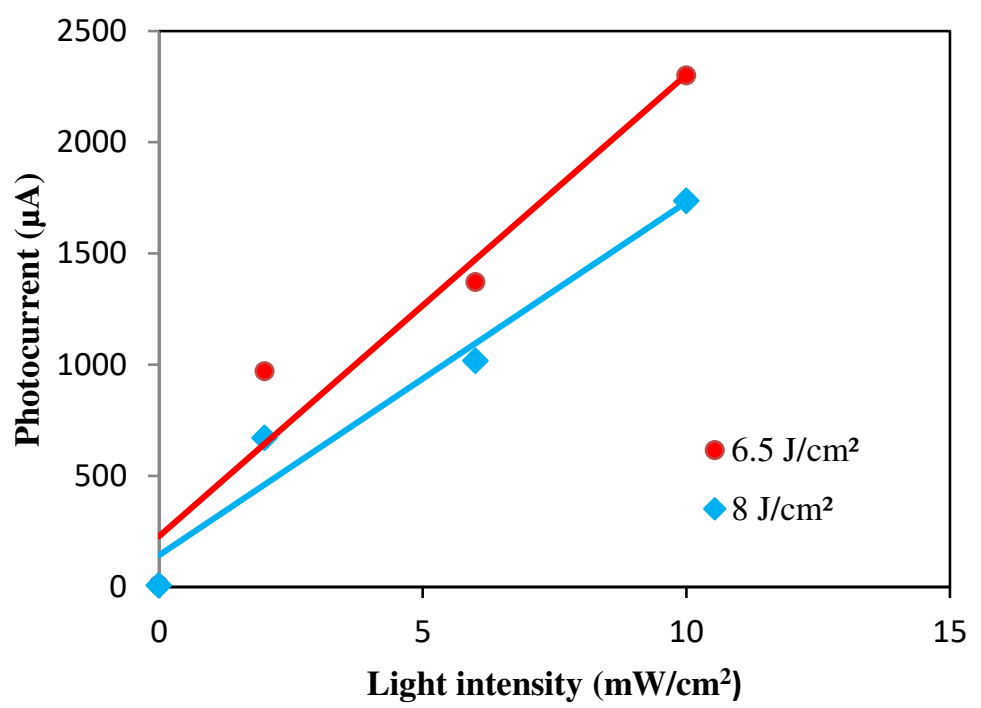

Fig.10. plot of BSCCO/Si photodetector v.s light intensity for thin film deposited with $6.5 \mathrm{~J} / \mathrm{cm}^{2}$ and $8 \mathrm{~J} / \mathrm{cm}^{2}$

Fig.11 shows the spectral responsivity plot of the BSCCO/Si photodetector. The responsivity of the photodetector $\left(R_{\lambda}\right)$ is calculated from

$$
R_{\lambda}=\frac{I_{p h}}{P}
$$

Where $\mathrm{I}_{\mathrm{ph}}$ is the photocurrent of the photodetector and is $\mathrm{P}$ is the incident power of the light at certain wavelength .As clearly seen in Fig.9, the responsivity of the photodetector prepared with $6.5 \mathrm{~J} / \mathrm{cm}^{2}$ is larger that of that prepared with $8 \mathrm{~J} / \mathrm{cm}^{2}$. The peak of the response of the photodetectors prepared with 6.5 and $8 \mathrm{~J} / \mathrm{cm}^{2}$ is found at 560 and $760 \mathrm{~nm}$, respectively. The shift in peak response could be ascribed to the absorption edge of the film. The responsivity of the 
photodetector prepared with $6.5 \mathrm{~J} / \mathrm{cm}^{2}$ is increased with wavelength up to $860 \mathrm{~nm}$, while it decreases after wavelength of $760 \mathrm{~nm}$ for photodetector prepared with $8 \mathrm{~J} / \mathrm{cm}^{2}$.The depletion region extended toward the substrate (silicon side) in the case of photodetector prepared with 8 $\mathrm{J} / \mathrm{cm}^{2}$ which leads to improvement of the responsivity of the photodetector for near infraread wavelengths. The maximum responsivity was $0.514 \mathrm{~A} / \mathrm{W}$ at $860 \mathrm{~nm}$ for photodetector prepared with $6.5 \mathrm{~J} / \mathrm{cm}^{2}$.

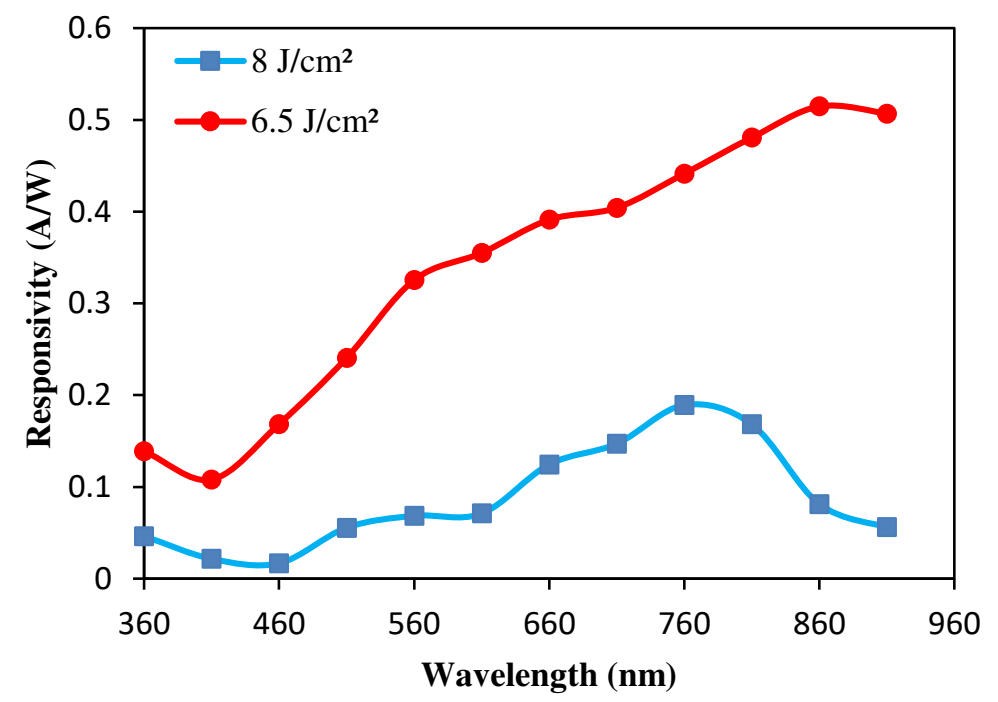

Fig. (11) Spectral responsivity plot of the BSCCO/Si photodetector for thin film deposited with $6.5 \mathrm{~J} / \mathrm{cm}^{2}$ and $8 \mathrm{~J} / \mathrm{cm}^{2}$

The external quantum efficiency (EQE) of the photodetector was determined from

$$
E Q E=\frac{1240 I_{p h}}{\lambda P} \times 100
$$

Fig.12 shows the EQE of the photodetector as a function of wavelength. The value of EQE of the photodetector prepared with $6.5 \mathrm{~J} / \mathrm{cm}^{2}$ was larger than of that prepared with $8 \mathrm{~J} / \mathrm{cm}^{2}$. The maximum value of $\mathrm{EQE}$ was $74 \%$ at $860 \mathrm{~nm}$ which is comparable to the silicon based heterojunction photodetector [24-26]. 


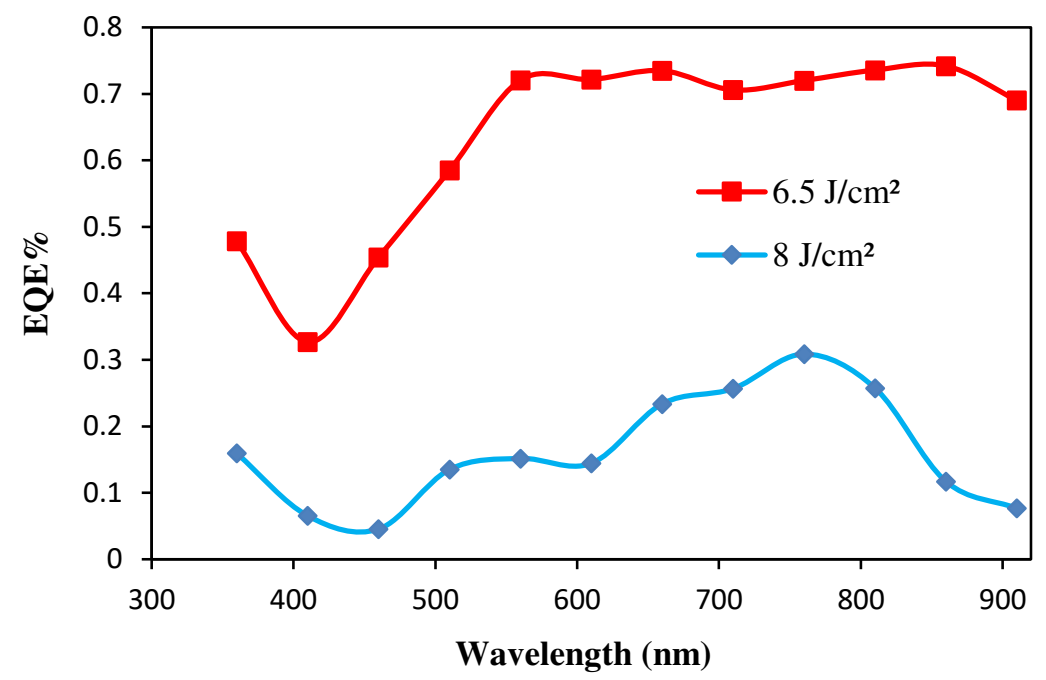

Fig.(12) EQE of the photodetector as a function of wavelength for thin film deposited with $6.5 \mathrm{~J} / \mathrm{cm}^{2}$ and 8 $\mathrm{J} / \mathrm{cm}^{2}$

The detectivity $\left(\mathrm{D}^{*}\right)$ of the photodetector can be defined as the minimum detectable power which considers the most important figures of merit of the photodetectors. It depends on the responsivity and noise current (In) as shown in the following relationship

$$
D^{*}=\frac{R_{\lambda}(A \Delta f)^{0.5}}{I_{n}}
$$

Where $\mathrm{A}$ is the sensitive area of the photodetector and $(\Delta \mathrm{f})$ is the bandwidth of the photodetector. Fig.13 shows the detectivity as a function of the wavelength of the photodetectors prepared at 6.5 and $8 \mathrm{~J} / \mathrm{cm}^{2}$ at bias voltage of $7.5 \mathrm{~V}$. The detectivity of the photodetector prepared with 6.5 $\mathrm{J} / \mathrm{cm}^{2}$ is higher than of that deposited with $8 \mathrm{~J} / \mathrm{cm}^{2}$ due to its low noise current and high responsivity. The maximum detectivity of the photodetector prepared at $6.5 \mathrm{~J} / \mathrm{cm}^{2}$ was $2.57 \times 10^{11}$ Jones at $860 \mathrm{~nm}$, while the maximum detectivity of the photodetector prepared with $8 \mathrm{~J} / \mathrm{cm}^{2}$ was $9.4 \times 10^{10}$ Jones at $760 \mathrm{~nm}$. This can be related to the structural defects and surface traps formed at the interface between the BSCCO film and silicon for the photodetector prepared at $8 \mathrm{~J} / \mathrm{cm}^{2}$. The values of the noise equivalent power NEP of the photodetectors prepared with 6.5 and $8 \mathrm{~J} / \mathrm{cm}^{2}$ were $3.8 \mathrm{pW}$ and $11 \mathrm{pW}$, respectively. 


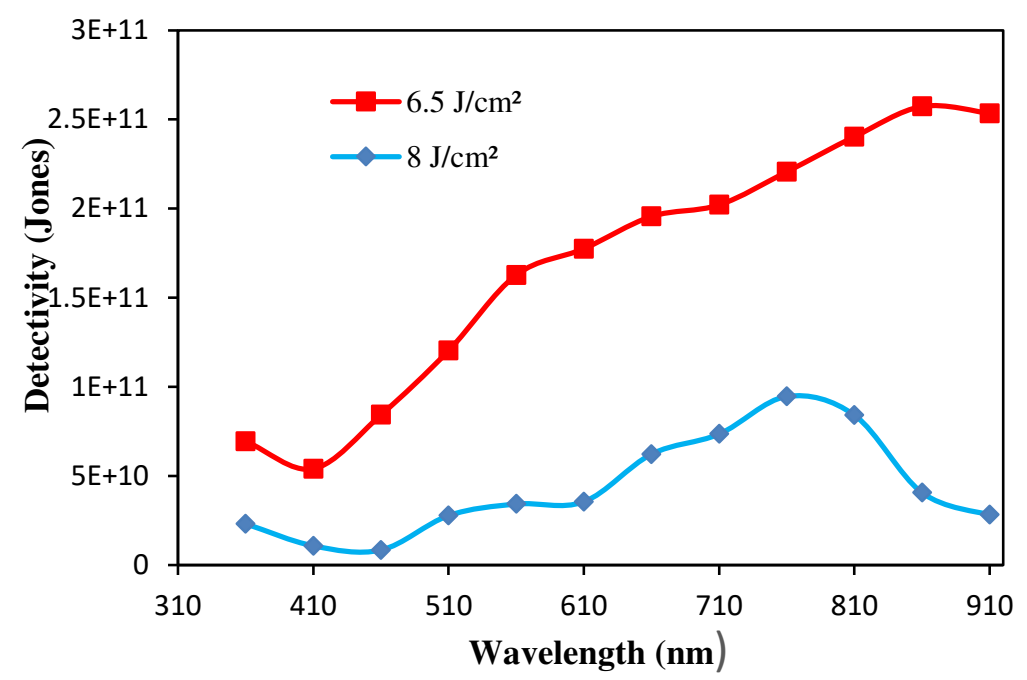

Fig. (13) Detectivity of BSCCO/Si film photodetector prepared at $6.5 \mathrm{~J} / \mathrm{cm}^{2}$ and $8 \mathrm{~J} / \mathrm{cm}^{2}$

\section{Conclusions}

$\mathrm{Bi}_{2} \mathrm{Sr}_{2} \mathrm{CaCu}_{2} \mathrm{O}_{x}$ film has been prepared by pulsed laser deposition technique, and $\mathrm{Bi}_{2} \mathrm{Sr}_{2} \mathrm{CaCu}_{2} \mathrm{O}_{\mathrm{x}}$ /Si heterojunction photodetectors were fabricated. Results of $\mathrm{x}$-ray diffraction showed that the structural properties of the deposited films were strongly depended on the laser energy density. The film prepared with $8 \mathrm{~J} / \mathrm{cm}^{2}$ revealed the grains are highly oriented along (006) plane. The optical energy gap of the film decreased from $2.2 \mathrm{eV}$ to $1.6 \mathrm{eV}$ when the laser energy density increased from 6.5 to $8 \mathrm{~J} / \mathrm{cm}^{2}$. Results of SEM confirmed that the grown film consisted of spherical grains with different sizes and the grains agglomeration and aggregation were found to be increased as laser energy density increased. The electrical properties of $\mathrm{BSCCO} / \mathrm{Si}$ heterojunction revealed that current transport mechanism is recombination-tunneling type. The ideality factor of the heterojunction increased and rectification factor decreased as laser energy density decreased. The figures of merit of the photodetector; namely responsivity, quantum efficiency, detectivity and NEP were estimated. The best photodetector has responsivity of 0.514 $\mathrm{A} / \mathrm{W}, \mathrm{EQE}$ of $74 \%$ and $\mathrm{D}^{*}$ of $2.57 \times 10^{11}$ Jones at $860 \mathrm{~nm}$. Based on the obtained results, the BSCCO film can be suggested to be good materials for high photosensitivity Vis-NIR heterojunction photodetector. 


\section{Acknowledgements}

The authors would like to thank the department of Applied Science for support this research study.

\section{Funding statement}

No fund has been received for this research study.

\section{Compliance with Ethical Standards}

Competing Interests: The authors have declared that no competing interests exist

\section{Conflict of interest}

The authors have declared no conflict of interest

\section{References}

1. Maeda, H., Tanaka, Y., Fukutomi, M., \& Asano, T. A. new High-T c $_{\mathrm{c}}$ oxide superconductor without a rare earth element. Japanese Journal of Applied Physics, 27(2A), L209. (1988).

2. Kharissova, O. V., Kopnin, E. M., Maltsev, V. V., Leonyuk, N. I., León-Rossano, L. M., Pinus, I. Y., \& Kharisov, B. I. Recent advances on bismuth-based 2223 and 2212 superconductors: synthesis, chemical properties, and principal applications. Critical Reviews in Solid State and Materials Sciences, 39(4), 253-276. (2014).

3. Jeffrey, C., Blanca, G. R. S., Vitug, J. R., Garcia, W. O., \& Sarmago, R. V. Stoichiometric transfer of material in the infrared pulsed laser deposition of yttrium doped Bi-2212 films. Physica C: Superconductivity, 471(11-12), 378-383. (2011).

4. Yildirim, G., Varilci, A., \& Terzioglu, C. Anisotropic nature and scaling of thermally activated dissipation mechanism in Bi-2223 superconducting thin film. Journal of alloys and compounds, 554, 327-334. (2013).

5. Oktem, B., Bozbey, A., Avci, I., Tepe, M., Abukay, D., \& Fardmanesh, M. The superconducting transition width and illumination wavelength dependence of the response of $\mathrm{MgO}$ substrate $\mathrm{YBCO}$ transition edge bolometers. Physica C: Superconductivity, 458(1-2), 6-11 . (2007)

6. Ozyuzer, L., Koshelev, A. E., Kurter, C., Gopalsami, N., Li, Q., Tachiki, M., \& Welp, U. Emission of coherent THz radiation from superconductors. Science, 318(5854), 12911293. (2007). 
7. Fujino, H., Kume, E., Sugimata, E., Zhao, X., \& Sakai, S. Characteristics of intrinsic Josephson junctions using a $\mathrm{Bi}_{2} \mathrm{Sr}_{2} \mathrm{CaCu}_{2} \mathrm{O}_{\mathrm{x}}$ thin film estimated overall in a chip. Physica C: Superconductivity, 412, 1410-1413. (2004).

8. Anderson, P. W. Twenty-five years of high-temperature superconductivity A personal review. In Journal of Physics: Conference Series (Vol. 449, No. 1, p. 012001). IOP Publishing. (2013).

9. Omar, M. A. Elementary solid state physics: principles and applications. Pearson Education India. (1975).

10. Ha, D. H., Min, H. S., Lee, K. W., Byon, S., Han, G. Y., \& Lee, H. K. Effects of cation substitution on the oxygen loss in YBCO superconductors. Journal -Korean Physics society, 39, 1041-1045. (2001).

11. Choi, C. H. Impurity-induced magnetic field in time-reversal symmetry-breaking superconductors. Journal of the Korean Physical Society, 40(3), 480-483. (2002).

12. Dijkkamp, D., Venkatesan, T., Wu, X. D., Shaheen, S. A., Jisrawi, N., MinLee, Y. H.\& Croft, M. Preparation of $\mathrm{YBaCu}$ oxide superconductor thin films using pulsed laser evaporation from high Tc bulk material. Applied Physics Letters, 51(8), 619-621. (1987).

13. Wu, X. D., Dijkkamp, D., Ogale, S. B., Inam, A., Chase, E. W., Miceli, P. F., \& Venkatesan, T. Epitaxial ordering of oxide superconductor thin films on (100) $\mathrm{SrTiO}_{3}$ prepared by pulsed laser evaporation. Applied physics letters, 51(11), 861-863. (1987).

14. Ismail, R. A., Mousa, A. M., \& Shaker, S. S. Preparation of visible-enhanced $\mathrm{PbI}_{2} / \mathrm{MgO} / \mathrm{Si}$ heterojunction photodetector. Optik, 202, 163585. (2020).

15. Ismail, R. A., Mousa, A. M., \& Shaker, S. S. Visible-enhanced silver-doped $\mathrm{PbI}_{2}$ nanostructure/Si heterojunction photodetector: effect of doping concentration on photodetector parameters. Optical and Quantum Electronics ,51:362. (2019)

16. Ismail, R. A., Mousa, A. M., \& Shaker, S. S. Improved growth conditions of pulsed laserdeposited $\mathrm{PbI}_{2}$ nanostructure film: towards high-photosensitivity $\mathrm{PbI}_{2} / \mathrm{CNTs} / \mathrm{Si}$ photodetectors. Journal of Materials Science: Materials in Electronics, 30(23), 2085020859. (2019).

17. You Lixing, Wu Peiheng, Cai Weixing, Yang Senzu1, Wang Huabing \& Kang Lin, Fabrication and characteristics of intrinsic Josephson junctions in $\mathrm{Bi}_{2} \mathrm{Sr}_{2} \mathrm{CaCu}_{2} \mathrm{O}_{8+\mathrm{x}}$ single crystals, Chinese Science BulletinVol. 48 No.124_27. (2003).

18. Jeffrey C. De Vero, Jacque Lynn F. Gabayno, Wilson O. Garcia, Roland V. Sarmago, Growth evolution of $\mathrm{Bi}_{2} \mathrm{Sr}_{2} \mathrm{CaCu}_{2} \mathrm{O}_{8}$ thin films deposited by infrared $(1064 \mathrm{~nm})$ pulsed laser deposition, Physica C 470, 149-154. (2010).

19. Ismail, R. A., Mousa, A. M., Khashan, K. S., Mohsin, M. H., \& Hamid, M. K. Synthesis of $\mathrm{PbI}_{2}$ nanoparticles by laser ablation in methanol. Journal of Materials Science: Materials in Electronics, 27(10), 10696-10700. (2016).

20. Hussein, B. H., Mahdi, S. H., Makki, S. A., \& Al-Maiyaly, B. K. Synthesis and Study the Structure, electrical and optical properties of $\mathrm{Bi}_{2-\mathrm{x}} \mathrm{Cd}_{\mathrm{x}} \mathrm{Sr}_{2} \mathrm{Ca}_{2} \mathrm{Cu}_{3} \mathrm{O}_{10}+\delta$ thin film Superconductors. Energy Procedia, 157, 100-110. (2019).

21. Ismail, R. A., Hassan, K. I., Abdulrazaq, O. A., \& Abode, W. H. Optoelectronic 
properties of $\mathrm{CdTe} / \mathrm{Si}$ heterojunction prepared by pulsed Nd: YAG-laser deposition technique. Materials science in semiconductor processing, 10(1), 19-23. (2007).

22. Ismail, R. A. Fabrication and characterization of photodetector based on porous silicon. e-Journal of Surface Science and Nanotechnology, 8, 388-391. (2010).

23. Ismail, R. A., Khashan, K. S., \& Mahdi, R. O. Characterization of high photosensitivity nanostructured $4 \mathrm{H}-\mathrm{SiC} / \mathrm{p}-\mathrm{Si}$ heterostructure prepared by laser ablation of silicon in ethanol. Materials Science in Semiconductor Processing, 68, 252-261. (2017).

24. Ismail, R. A., Khashan, K. S., Jawad, M. F., Mousa, A. M., \& Mahdi, F. Preparation of low cost $\mathrm{n}-\mathrm{ZnO} / \mathrm{MgO} / \mathrm{p}$-Si heterojunction photodetector by laser ablation in liquid and spray pyrolysis. Materials Research Express, 5(5), 055018. (2018).

25. Ismail, R. A., Mousa, A. M., \& Shaker, S. S. Effect of substrate temperature on the characteristic of $\mathrm{p}-\mathrm{PbI}_{2} / \mathrm{n}-\mathrm{Si}$ heterojunction grown by pulsed laser deposition technique. Materials Science in Semiconductor Processing, 99, 165-174. (2019)

26. Shaker, S. S., Ismail, R. A., \& Ahmed, D. S. Preparation of Bismuth Oxide Nanoplatelets/Si Photodetector by Laser Ablation in Liquid Under Effect of an External Magnetic Field. Silicon, 1-7. (2020). 
Figures

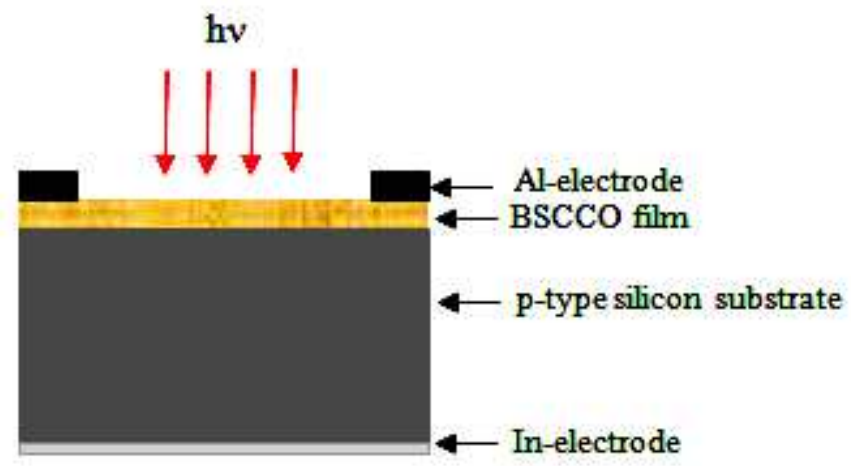

\section{Figure 1}

The schematic diagram of cross sectional view of $\mathrm{BSCCO} / \mathrm{p}-\mathrm{Si}$

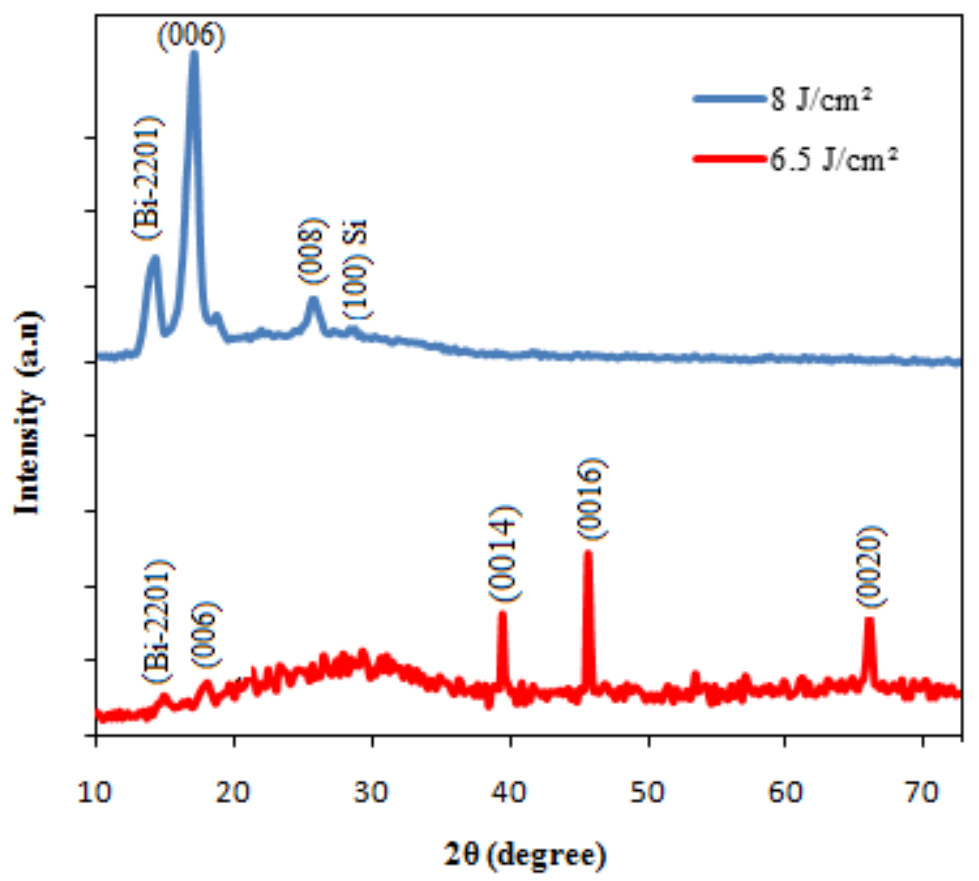

Figure 2

XRD of BSCCO films prepared at laser energy density of 6.5 and $8.1 \mathrm{~J} / \mathrm{cm} 2$ 


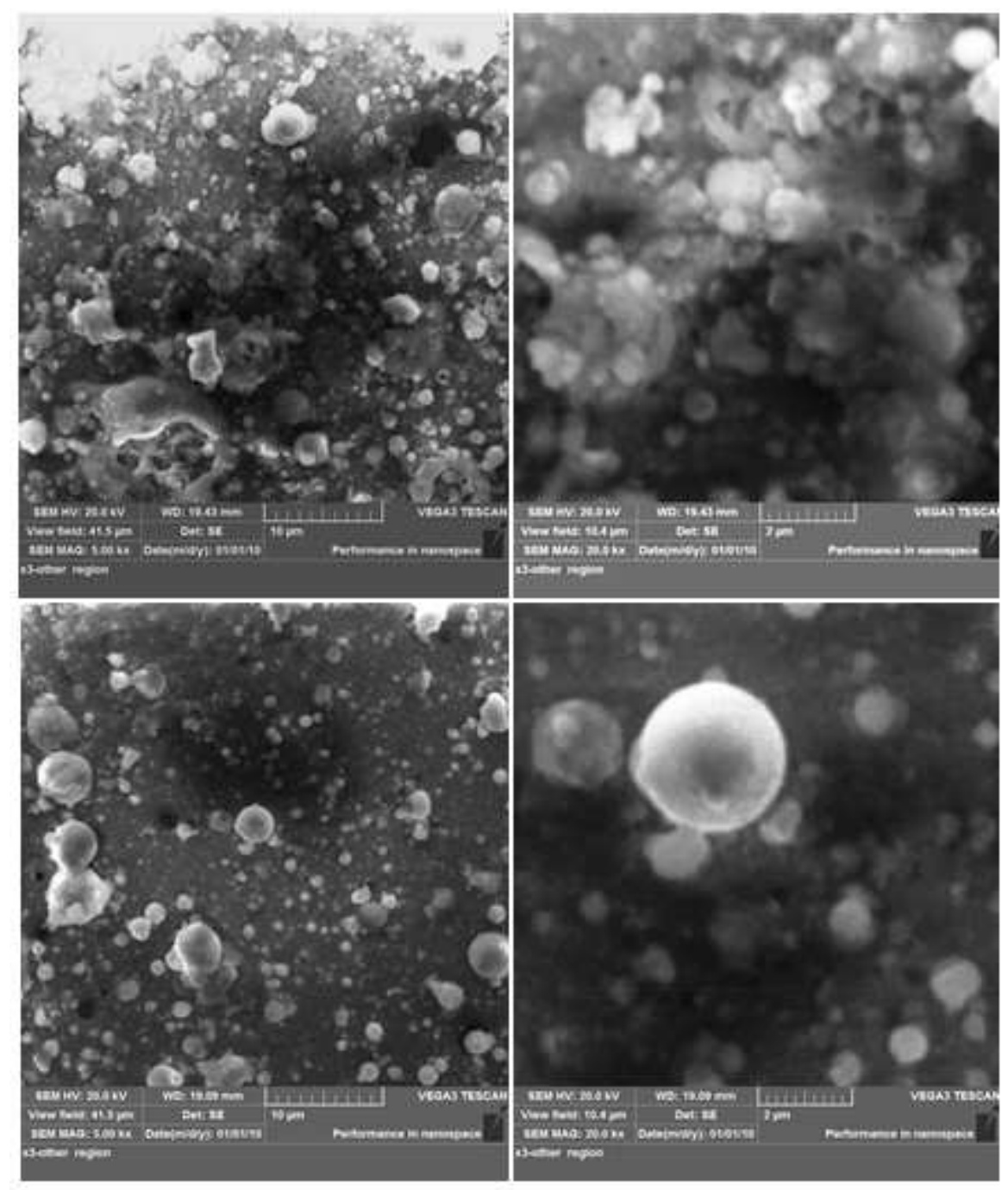

Figure 3

SEM images with two magnifications of BSCCO/Si film deposited with 6.5 and $8 \mathrm{~J} / \mathrm{cm} 2$ 

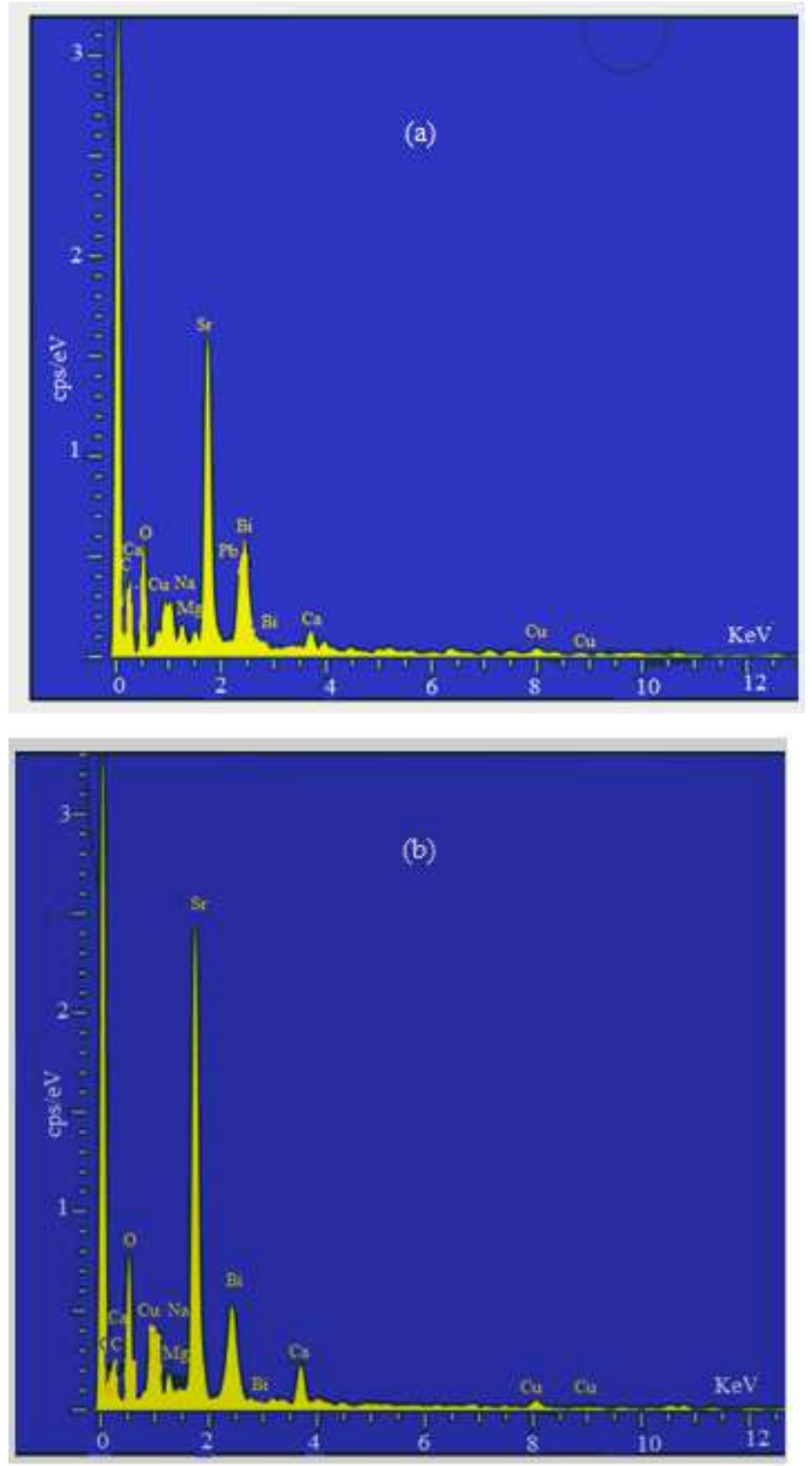

Figure 4

EDX spectra of BSCCO/Si film deposited with(a) $6.5 \mathrm{~J} / \mathrm{cm} 2$ and (b) $8 \mathrm{~J} / \mathrm{cm} 2$ 


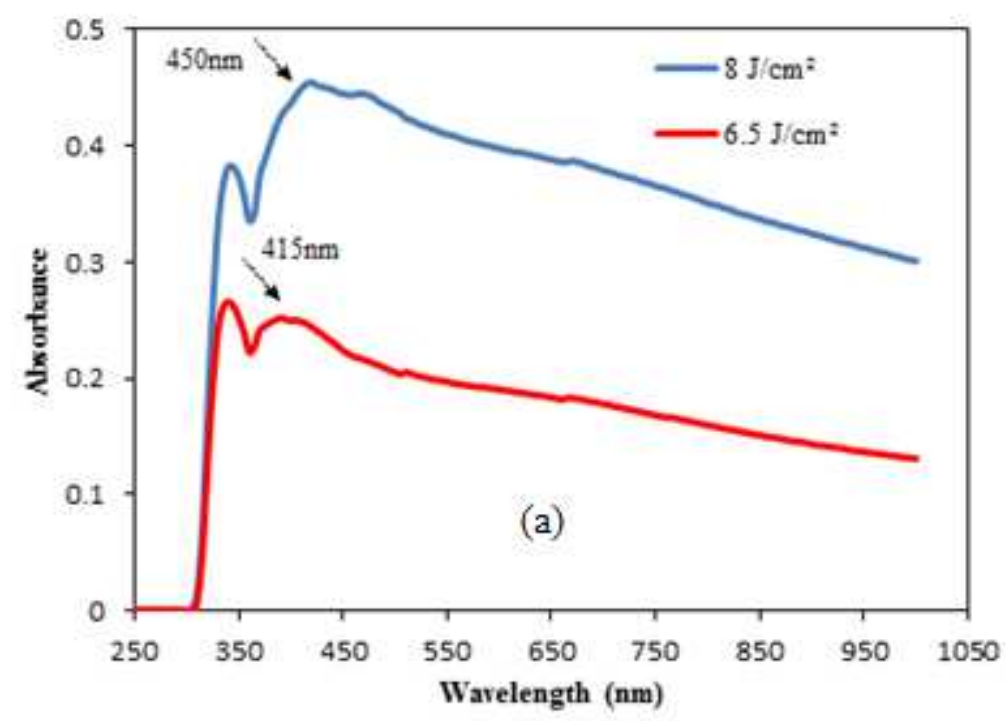

(b)

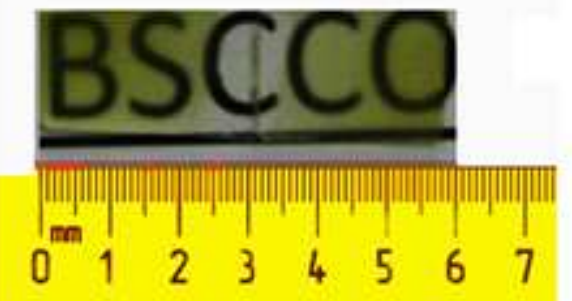

Figure 5

(a) Optical absorption of BSCCO/glass films deposited with $6.5 \mathrm{~J} / \mathrm{cm} 2$ and $8 \mathrm{~J} / \mathrm{cm} 2$ and (b) photograph of BSCCO films deposited on the glass substrate 

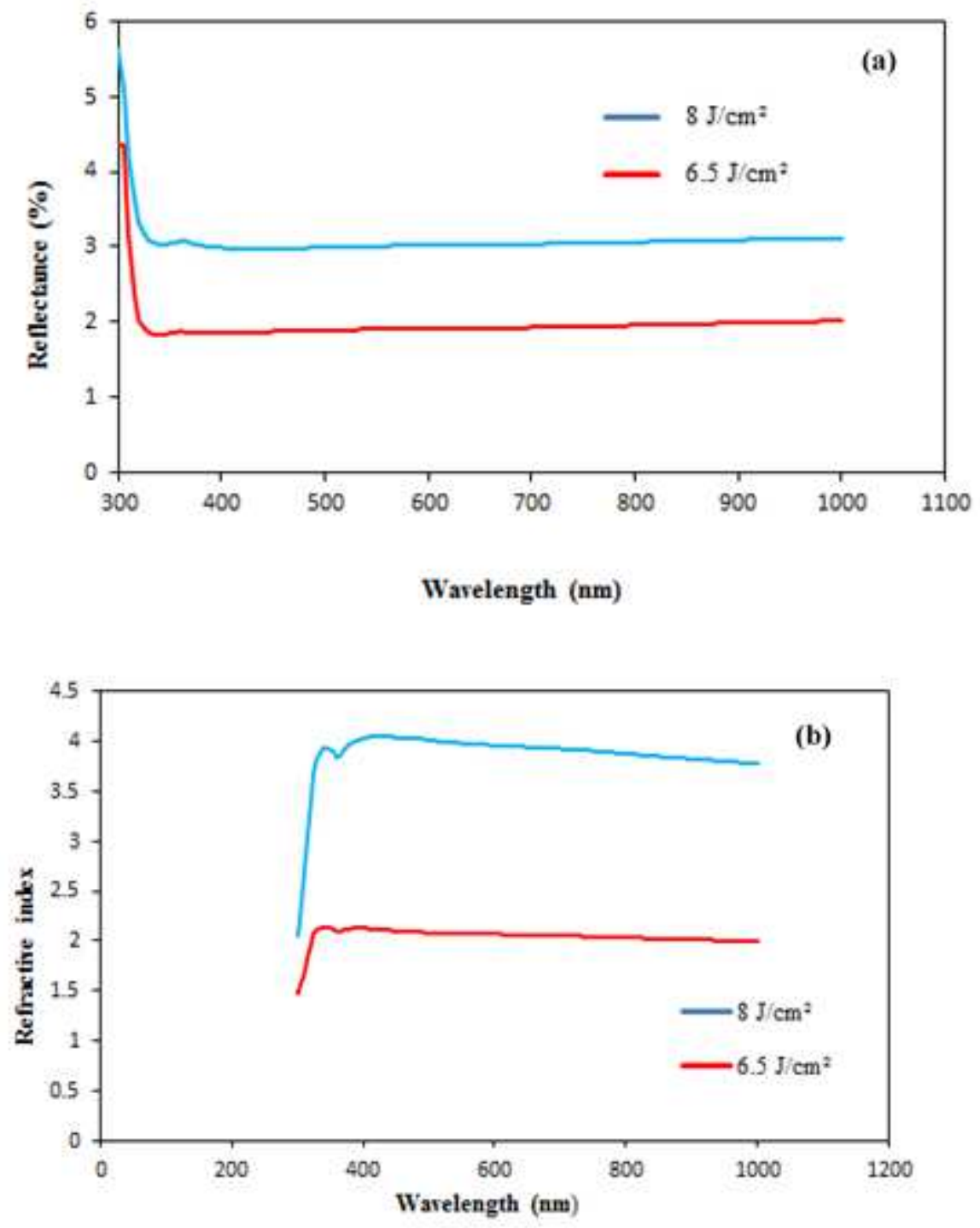

Figure 6

(a) The reflectance spectra and (b) refractive index of BSCCO films deposited with $6.5 \mathrm{~J} / \mathrm{cm} 2$ and 8 $\mathrm{J} / \mathrm{cm} 2$ 


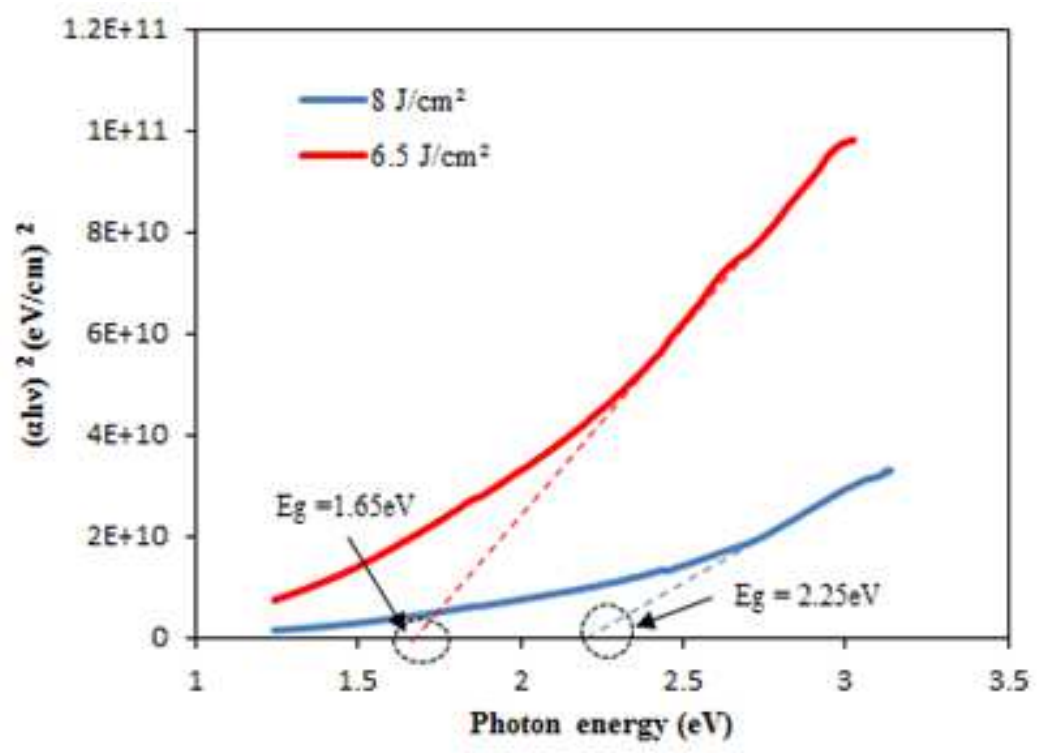

Figure 7

Optical energy gap of BSCCO film deposited with $6.5 \mathrm{~J} / \mathrm{cm} 2$ and $8 \mathrm{~J} / \mathrm{cm} 2$
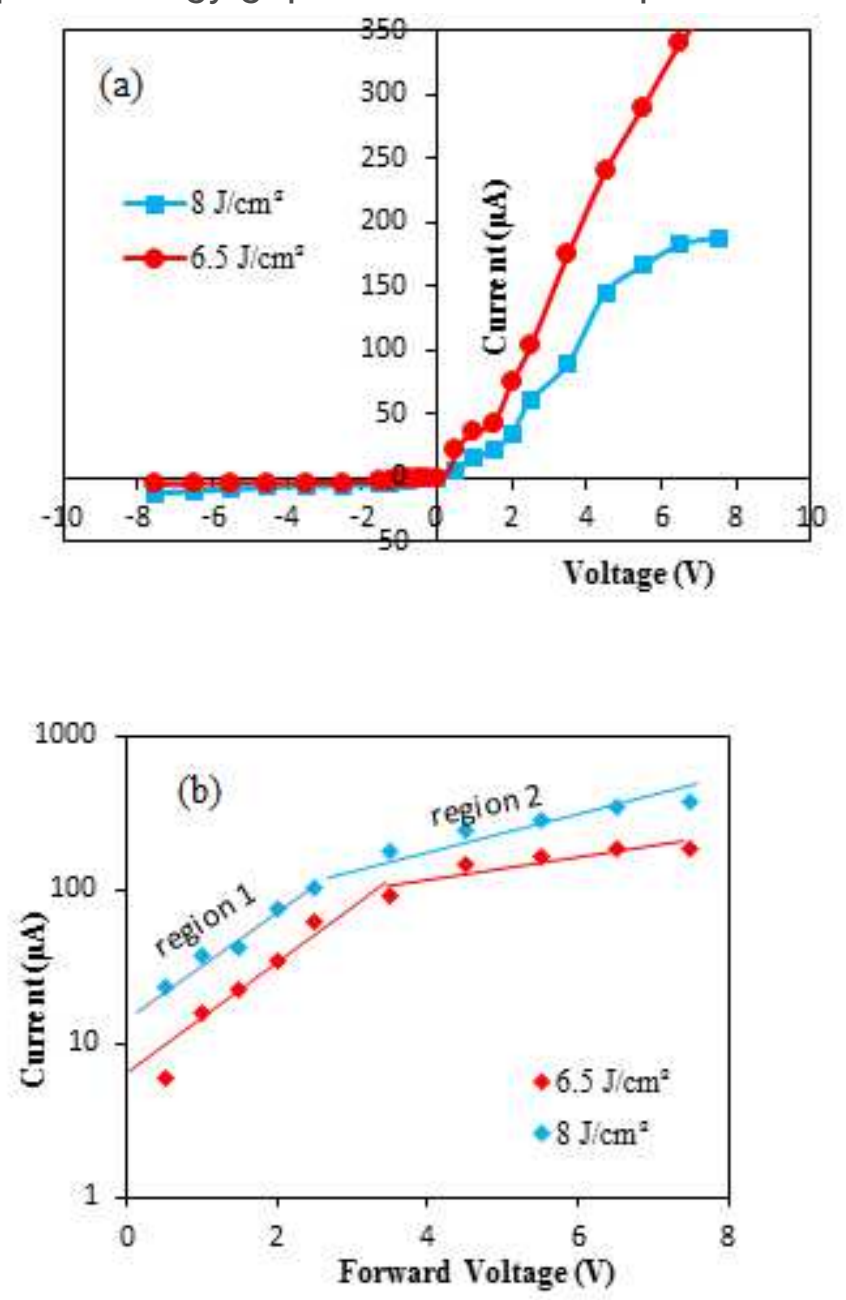

Figure 8 
(a) dark I-V characteristics of BSCCO/Si heterojunction at room temperature under forward and reverse directions (b) plot of semi-logarithmic If $-\mathrm{V}$
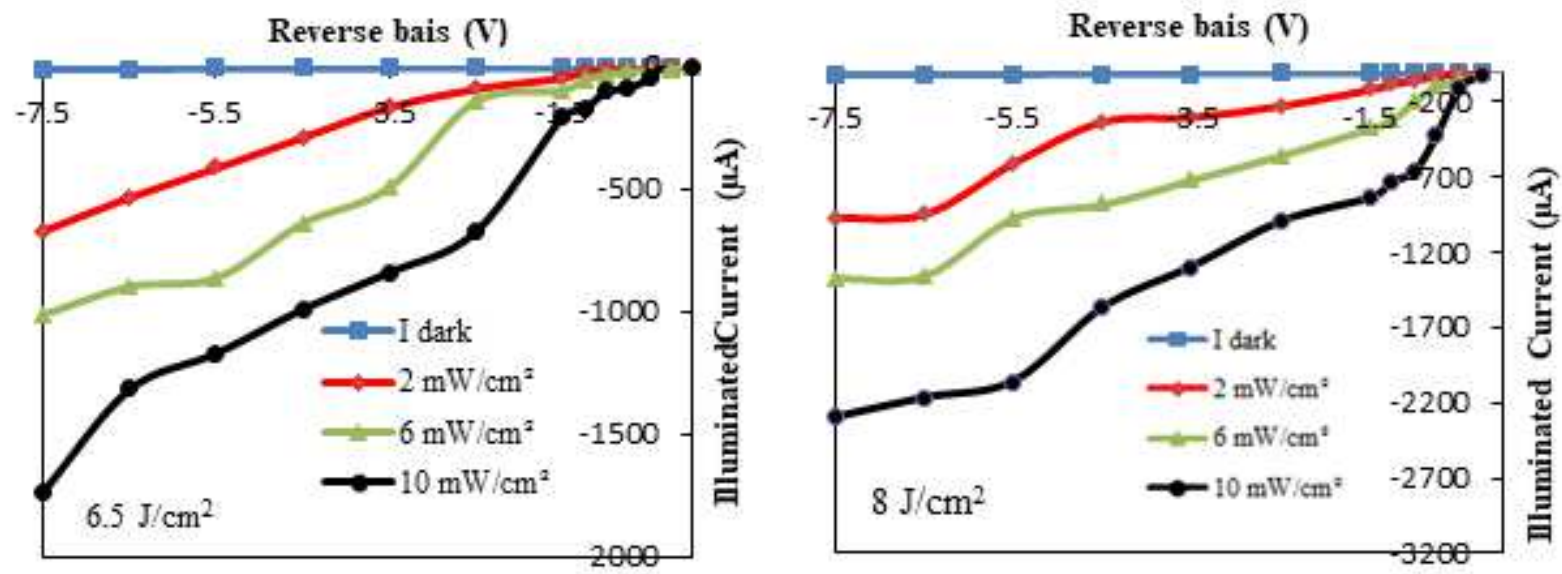

\section{Figure 9}

illuminated I-V characteristics at room temperature and different white light intensities for films deposited with $6.5 \mathrm{~J} / \mathrm{cm} 2$ and $8 \mathrm{~J} / \mathrm{cm} 2$

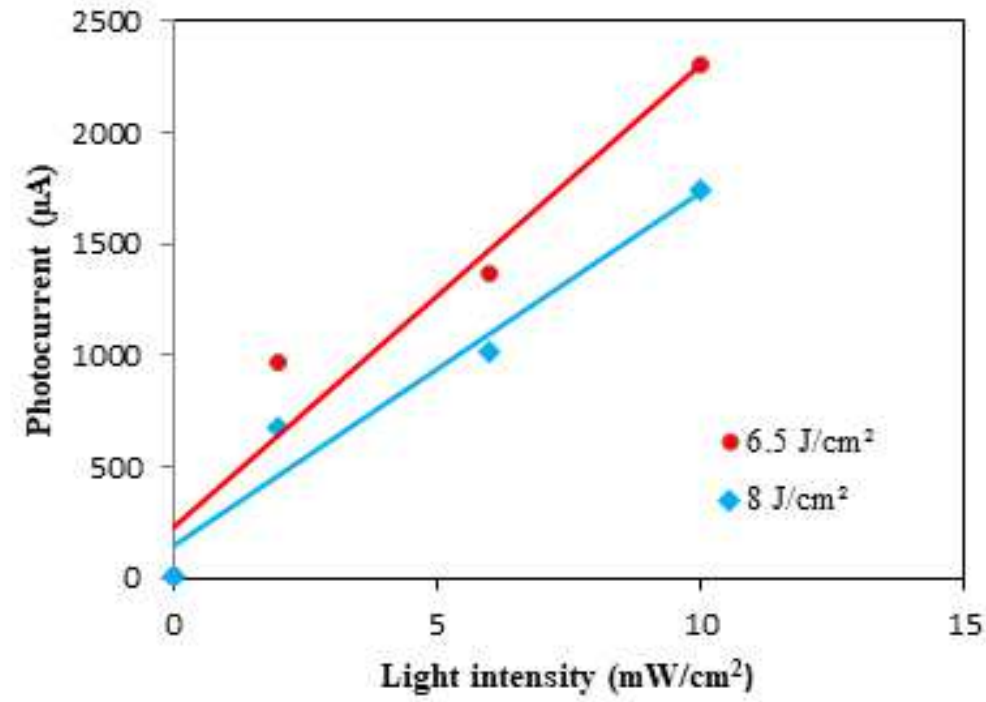

Figure 10

plot of BSCCO/Si photodetector v.s light intensity for thin film deposited with $6.5 \mathrm{~J} / \mathrm{cm} 2$ and $8 \mathrm{~J} / \mathrm{cm} 2$ 


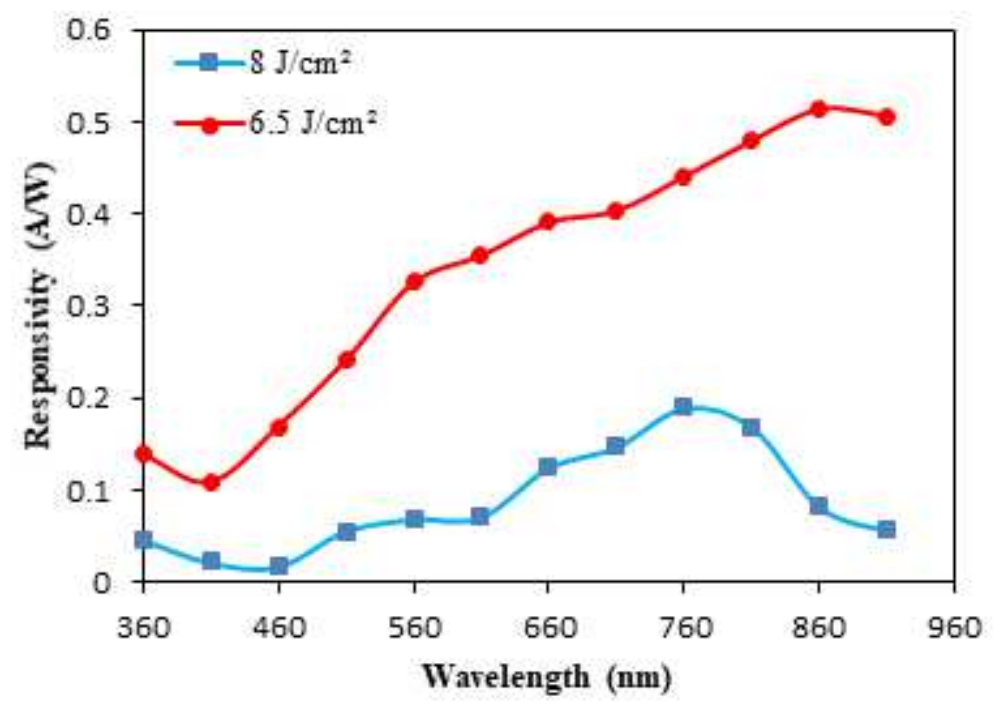

Figure 11

Spectral responsivity plot of the BSCCO/Si photodetector for thin film deposited with $6.5 \mathrm{~J} / \mathrm{cm} 2$ and 8 $\mathrm{J} / \mathrm{cm} 2$

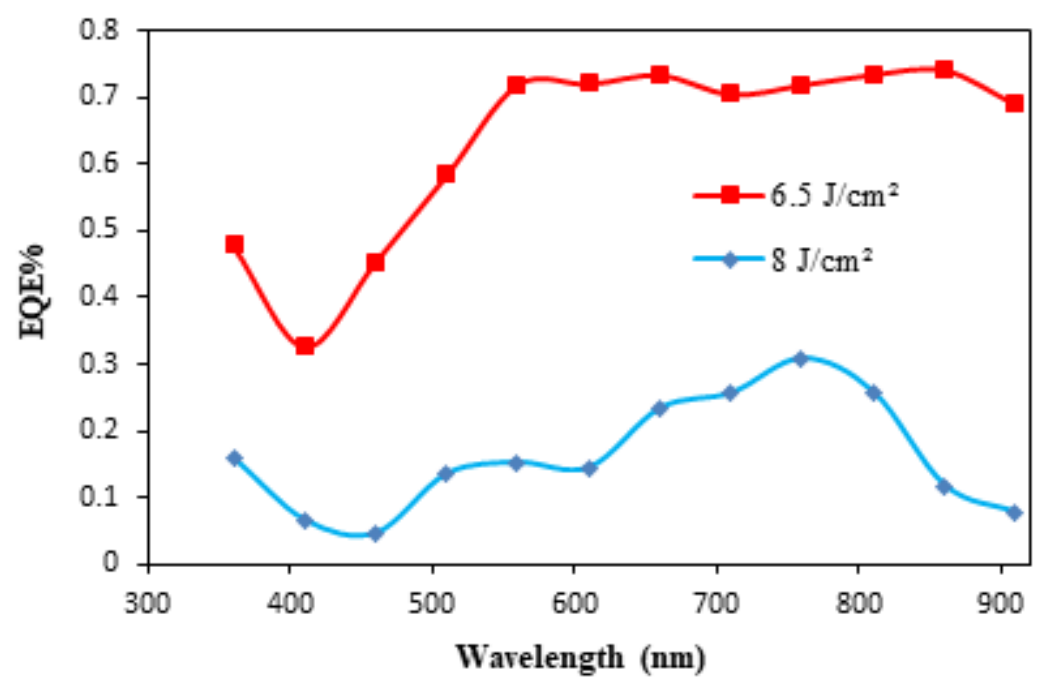

Figure 12

EQE of the photodetector as a function of wavelength for thin film deposited with $6.5 \mathrm{~J} / \mathrm{cm} 2 \mathrm{and} 8 \mathrm{~J} / \mathrm{cm} 2$ 


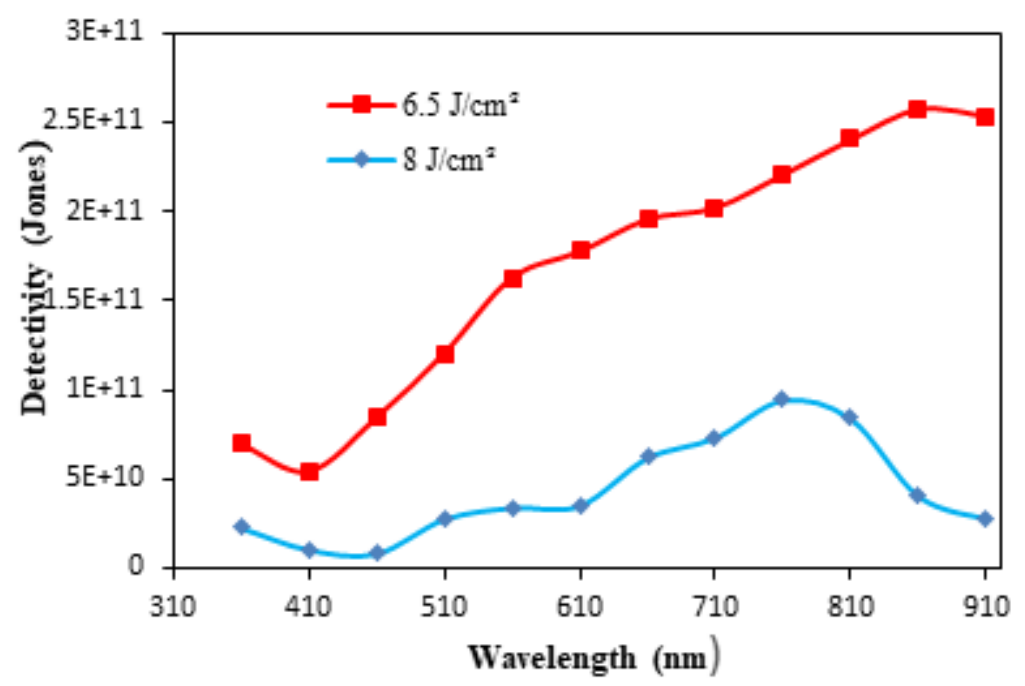

Figure 13

Detectivity of BSCCO/Si film photodetector prepared at $6.5 \mathrm{~J} / \mathrm{cm} 2$ and $8 \mathrm{~J} / \mathrm{cm} 2$ 